\title{
Knowledge and awareness of dental specialists, general dentists and dental assistants regarding SARS-CoV-2
}

\author{
Hafsa Qabool ${ }^{\mathrm{A}-\mathrm{F}}$, Rashna Hoshang Sukhia ${ }^{\mathrm{A}, \mathrm{C}, \mathrm{E}, \mathrm{F}}$, Mubassar Fida ${ }^{\mathrm{E}, \mathrm{F}}$ \\ Section of Dentistry (Orthodontics), Department of Surgery, Aga Khan University Hospital, Karachi, Pakistan \\ A - research concept and design; $\mathrm{B}$ - collection and/or assembly of data; $\mathrm{C}$ - data analysis and interpretation; \\ $D$ - writing the article; $E$ - critical revision of the article; $F$ - final approval of the article
}

Address for correspondence

Rashna Hoshang Sukhia

E-mail: rashna.aga@aku.edu

Funding sources

None declared

Conflict of interest

None declared

Received on December 21,2020

Reviewed on March 11, 2021

Accepted on March 25, 2021

Published online on August 31, 2021

Cite as

Qabool H, Sukhia RH, Fida M. Knowledge and awareness

of dental specialists, general dentists and dental assistants regarding SARS-CoV-2. Dent Med Probl. 2021;58(3):285-290. doi:10.17219/dmp/134964

DOI

$10.17219 / \mathrm{dmp} / 134964$

Copyright

๑ 2021 by Wroclaw Medical University

This is an article distributed under the terms of the

Creative Commons Attribution 3.0 Unported License (CC BY 3.0)

(https://creativecommons.org/licenses/by/3.0/).

\begin{abstract}
Background. Severe acute respiratory syndrome coronavirus 2 (SARS-CoV-2) has had drastic effects among healthcare professionals.

Objectives. This study aimed to assess knowledge and awareness among dental specialists, general dentists and dental assistants regarding standard patient care guidelines for minimizing the spread of the infection.
\end{abstract}

Material and methods. A survey-based cross-sectional study was conducted on a sample of 84 participants. The participants were divided into groups of dental specialists, general dentists and dental assistants. A modified version of a validated questionnaire was used to evaluate knowledge and awareness regarding SARS-CoV-2 as per the Centers for Disease Control and Prevention (CDC) guidelines. Data was analyzed using the one-way analysis of variance (ANOVA) and post-hoc Tukey's tests to assess differences in knowledge regarding the SARS-CoV-2 guidelines across the 3 groups. The simple linear regression analysis was used to examine factors influencing the knowledge scores.

Results. Among all dental specialists, 13 orthodontists, 9 operative dentists, 8 maxillofacial surgeons, 4 prosthodontists, and 1 periodontist responded to the survey. The mean knowledge scores of dental specialists, general dentists and dental assistants were 10.05 $\pm 2.10,9.95 \pm 2.30$ and $8.53 \pm 2.10$, respectively. Overall, we found a significant difference $(p=0.02)$ in the knowledge scores between the groups, and pairwise comparisons showed that there was a significant difference $(p=0.03)$ in the knowledge scores between dental specialists and dental assistants.

Conclusions. These findings suggest that hospitals should conduct mandatory workshops, training sessions and seminars to raise the awareness of the novel coronavirus pandemic and disinfection protocols, not only for specialists, but for all staff members.

Keywords: cross-infection, health knowledge, attitudes, practice 


\section{Introduction}

A wave of respiratory tract infections first occurred in Wuhan, China, in December 2019 and quickly became the leading challenge for public health globally. ${ }^{1}$ Due to similarities in the RNA genome to the virus found in the respiratory tract of individuals infected with severe acute respiratory syndrome coronavirus (SARS-CoV), the World Health Organization (WHO) named the novel coronavirus responsible for these infections SARS-CoV-2. ${ }^{2}$

The symptoms of the SARS-CoV-2 infection vary from person to person, and may range from mild fever and a dry cough to severe acute respiratory distress and cardiac arrhythmias due to low oxygen saturation. ${ }^{3,4}$ Studies ${ }^{4-6}$ have found that this virus is transmitted in the form of droplets via coughing, sneezing or talking with an infected person at a minimal distance. ${ }^{5,6}$ For this reason, SARS-CoV-2 is spreading all over the globe irrespective of socioeconomic status, race or continent. ${ }^{7,8}$ Due to the high mortality rate and rapid spread of the infection, healthcare professionals declared an emergency at hospitals to ensure patient care. $^{9-10}$ The WHO declared dental surgeons to be at the highest risk of infection among healthcare professionals, as SARS-CoV-2 is transmitted via oral and nasal secretions in the form of droplets. ${ }^{11}$ In addition, the probability of transmission is increased in this setting, as dental procedures can generate aerosol while using instrumentation in the oropharyngeal region. ${ }^{12-14}$

Due to the fear of SARS-CoV-2 transmission and lockdowns, private and public dental practices faced drastic consequences. However, due to unavoidable maxillofacial emergencies, dental clinics could not shut down completely. ${ }^{15}$ Therefore, dental surgeons had a huge responsibility to ensure patient safety and care while conducting emergency procedures. Patient safety can only be assured if dental surgeons and dental staff members are properly prepared and well aware of the COVID-19 pandemic situation. ${ }^{16}$

Researchers have observed that the signs and symptoms, mode and rate of transmission, survival, and rate of recovery/mortality of infected individuals vary geographically. ${ }^{10-14}$ However, the WHO provided standard patient care guidelines for healthcare setups all over the world. ${ }^{17}$ All dental professionals must be well aware of standard infection control protocols to ensure patient safety and care. ${ }^{18,19}$ This study aimed to assess knowledge and awareness among dental specialists, general dentists and dental assistants regarding the general features of SARS-CoV-2. The secondary objective of this study was to identify factors influencing the level of knowledge and awareness of dental healthcare professionals regarding standard patient care guidelines in controlling the spread of infection. Thus, the null hypothesis of this study was that there is no difference in the knowledge and awareness scores among dental healthcare professionals regarding patient care protocols during the SARS-CoV-2 pandemic.

\section{Material and methods}

A survey-based cross-sectional study was conducted in May-June 2020 after ethical approval was obtained from the institutional ethics review committee (No. 20205281-11488). A required sample size of 72 participants was calculated using one-sample mean online software (https://www2.ccrb.cuhk.edu.hk/stat/mean/osm_equivalence.htm), selecting a variance of 25 , based on an error of estimate of 5 , an equivalence limit of 2 , a confidence level of $95 \%$, and a power of $80 \%$. Considering the chances of dropouts, the sample size was inflated by $10 \%$, for a total of 84 participants. The participants were divided into 3 groups: dental specialists; general dentists; and dental assistants.

Data was collected using a modified version of a validated questionnaire designed by Khader et al. ${ }^{20}$ (Table 1 ) to evaluate the awareness of dental specialists, general dentists and dental assistants regarding SARS-CoV-2 as per the Centers for Disease Control and Prevention (CDC) guidelines. This questionnaire had 2 parts. The $1^{\text {st }}$ part included information on demographics, such as sex, age, workplace, and experience, and the $2^{\text {nd }}$ part consisted of questions regarding the knowledge and awareness of SARS-CoV-2. Among all the options, only one answer was considered to be correct. The maximum score any participant could secure was 15.

The survey was conducted via Google forms and participants were recruited using social media platforms. All participants were asked to fill out the hard and soft copies of the forms. Five reminders were sent to the nonresponders before exclusion. The recruitment of participants was done based on the following inclusion criteria: dental specialists with a minimum of 2 years of experience in any specialty; practicing general dentists with 16 years of education; and practicing dental assistants with a minimum of 12 years of education.

\section{Statistical analysis}

Data was analyzed using the IBM SPSS Statistics for Windows software, v. 23.0 (IBM Corp., Armonk, USA), and Software for Statistics and Data Science, v. 12.0 (StataCorp, College Station, USA). The Shapiro-Wilk test showed a normal distribution of the data. The descriptive analyses of the variables were reported using means $(M)$ and standard deviations $(S D)$. The one-way analysis of variance (ANOVA) was applied to assess differences in the scores of knowledge and awareness regarding SARS-CoV-2 guidelines across the 3 groups of dental healthcare professionals. Pairwise comparison were also performed using post-hoc Tukey's tests. In addition, the univariate and multivariate linear regression analyses were used to examine the influence of the variables on the knowledge and awareness scores regarding the SARS-CoV-2 pandemic. 
Table 1. Percentage [\%] of correct answers among the 3 groups of dental healthcare professionals

Knowledge and awareness regarding novel coronavirus disease 2019 (COVID-19) questionnaire

Dental healthcare professionals dental specialists $\quad$ general dentists $\quad$ dental assistants

\begin{tabular}{|c|c|c|c|c|}
\hline Q.1 & Where did the disease outbreak start? & 97.1 & 79.2 & 96.0 \\
\hline Q.2 & What is the name of the virus causing SARS-CoV-2 infection? & 45.7 & 41.7 & 40.0 \\
\hline Q.3 & What is the mode of transmission of this disease? & 31.0 & 50.0 & 48.0 \\
\hline Q.4 & Which age group is most susceptible to the disease? & 40.0 & 66.7 & 32.0 \\
\hline Q.5 & After how many days may an infected person show signs and symptoms? & 85.0 & 54.2 & 52.0 \\
\hline Q.6 & What are the signs and symptoms of mild SARS-CoV-2 infection? & 91.4 & 100.0 & 84.0 \\
\hline Q.7 & If a person had contact with an infected person, what should he/she do? & 71.4 & 83.3 & 52.0 \\
\hline Q.8 & What are the chances of recovery after getting infected with SARS-CoV-2? & 74.3 & 79.8 & 60.0 \\
\hline Q.9 & What should a person with a recent travel history and symptoms do? & 85.7 & 66.7 & 20.0 \\
\hline Q.10 & What is the incubation period of SARS-CoV-2? & 42.9 & 33.3 & 60.0 \\
\hline Q.11 & What are the possible complications of the SARS-CoV-2 infection? & 85.7 & 95.8 & 56.0 \\
\hline Q.12 & $\begin{array}{l}\text { Which profession is considered at the highest risk of being infected } \\
\text { with SARS-CoV-2 by the WHO? }\end{array}$ & 60.0 & 50.0 & 72.0 \\
\hline Q.13 & $\begin{array}{l}\text { What is the PPE protocol for dentists while treating an asymptomatic patient } \\
\text { with a history of exposure to a SARS-CoV-2- positive patient? }\end{array}$ & 97.1 & 70.8 & 96.0 \\
\hline Q.14 & $\begin{array}{l}\text { Which of the following hand hygiene techniques can prevent the transmission } \\
\text { of infection among dentists? }\end{array}$ & 80.0 & 37.5 & 48.0 \\
\hline .15 & What is the preferred method of hand hygiene for healthcare professionals? & 17.1 & 37.5 & 32.0 \\
\hline
\end{tabular}

PPE - personal protective equipment.

\section{Results}

\section{Demographics}

A summary of the descriptive analysis of all variables among the 3 groups is shown in Table 2. The sample included 45 males and 39 females. The comparison of scores across sex found a significant difference $(p=0.03)$ in knowledge in the univariate analysis.
The mean age of the total sample was $35.17 \pm 9.5$ years. A comparable mean age was observed across the groups of dental specialists, general dentists and dental assistants. Among dental specialists, 13 were orthodontists, 9 were operative dentists, 8 were maxillofacial surgeons, 4 were prosthodontists, and 1 was a periodontist.

Table 2. Descriptive statistics for the participants

\begin{tabular}{|c|c|c|c|c|c|}
\hline Profession & $\begin{array}{l}\text { Sex } \\
n(\%)\end{array}$ & $\begin{array}{c}\text { Age } \\
\text { [years] } \\
M \pm S D\end{array}$ & $\begin{array}{c}\text { Experience } \\
\text { [years] } \\
M \pm S D\end{array}$ & $\begin{array}{c}\text { Workplace } \\
n\end{array}$ & $\begin{array}{c}\text { Knowledge scores } \\
M \pm S D\end{array}$ \\
\hline Dental assistants & $\begin{aligned} M & =17(68.0) \\
F & =8(32.0)\end{aligned}$ & $34.6 \pm 11.4$ & $8.8 \pm 6.8$ & $\begin{aligned} \mathrm{PuH} & =19 \\
\mathrm{PH} & =4 \\
\mathrm{PC} & =2\end{aligned}$ & $8.7 \pm 2.1$ \\
\hline General dentists & $\begin{array}{l}M=13(54.2) \\
F=11(45.8)\end{array}$ & $31.5 \pm 5.8$ & $8.7 \pm 7.4$ & $\begin{aligned} \mathrm{PuH} & =14 \\
\mathrm{PH} & =5 \\
\mathrm{PC} & =5\end{aligned}$ & $9.9 \pm 2.6$ \\
\hline Orthodontists & $\begin{array}{l}M=5(38.5) \\
F=8(61.5 \%)\end{array}$ & $35.6 \pm 4.8$ & $10.0 \pm 5.2$ & $\begin{array}{l}\mathrm{PuH}=2 \\
\mathrm{PH}=10 \\
P C=1\end{array}$ & $10.4 \pm 1.6$ \\
\hline Operative dentists & $\begin{array}{c}M=2(22.2) \\
F=7(77.8)\end{array}$ & $30.5 \pm 7.0$ & $8.2 \pm 5.3$ & $\begin{array}{c}\mathrm{PuH}=2 \\
\mathrm{PH}=7\end{array}$ & $10.0 \pm 1.2$ \\
\hline Maxillofacial surgeons & $\begin{array}{c}M=3(37.5) \\
F=5(62.5)\end{array}$ & $45.8 \pm 9.5$ & $23.6 \pm 12.5$ & $\begin{array}{l}\mathrm{PuH}=2 \\
\mathrm{PH}=6\end{array}$ & $89.2 \pm 3.7$ \\
\hline Prosthodontists & $M=4(100)$ & $47.2 \pm 5.9$ & $19.0 \pm 1.1$ & $\mathrm{PH}=4$ & $10.2 \pm 1.2$ \\
\hline Periodontists & $M=1(100)$ & $36.0 \pm 0.0$ & $4.0 \pm 0.0$ & $\mathrm{PH}=1$ & $12.0 \pm 1.1$ \\
\hline
\end{tabular}

$N=84 ; \mathrm{M}$ - male; F - female; $M$ - mean; SD - standard deviation; $\mathrm{PuH}$ - public hospital; $\mathrm{PH}$ - private hospital; $\mathrm{PC}$ - private clinic. 


\section{Knowledge scores regarding SARS-CoV-2}

The mean knowledge score for dental specialists was $10.05 \pm 2.10$, for general dentists $-9.95 \pm 2.30$ and for dental assistants $-8.53 \pm 2.10$ (Table 3 ). There was an overall significant difference $(p=0.02)$ in the knowledge and awareness scores across these groups of dental professionals. Pairwise comparisons revealed a significant difference $(p=0.03)$ in the knowledge and awareness scores between dental specialists and dental assistants (Table 4).

Table 3. Comparison of the knowledge scores across the groups of dental healthcare professionals (one-way ANOVA)

\begin{tabular}{|c|c|c|}
\hline Profession & Knowledge scores & $p$-value \\
\hline $\begin{array}{l}\text { Dental specialists } \\
n=35\end{array}$ & $10.05 \pm 2.10$ & \multirow{3}{*}{$0.02^{*}$} \\
\hline $\begin{array}{l}\text { General dentists } \\
n=24\end{array}$ & $9.95 \pm 2.30$ & \\
\hline $\begin{array}{l}\text { Dental assistants } \\
n=25\end{array}$ & $8.53 \pm 2.10$ & \\
\hline
\end{tabular}

Among all dental specialists, we found that the periodontist and orthodontists were well aware of the general CDC guidelines, with the mean scores of $12.0 \pm 1.1$ and $10.4 \pm 1.6$, respectively. The mean scores of operative dentists $(10.0 \pm 1.2)$ were comparable with those of orthodontists (Table 2). The regression model showed that there were no significant differences in scores between the specialties (Table 5 and Table 6).

We also found that almost $97 \%$ of dental healthcare professionals responded accurately with regard to the origin of SARS-CoV-2 infection and its initial symptoms.

Table 4. Pairwise comparisons among dental healthcare professionals (Tukey's post hoc test)

\begin{tabular}{|l|l|}
\multicolumn{1}{|c|}{ Comparison } & $p$-value \\
\hline Dental specialists vs dental assistants & $0.03^{*}$ \\
Dental specialists vs general dentists & 0.98 \\
General dentists vs dental assistants & 0.07 \\
\hline
\end{tabular}

$N=84 ;{ }^{*}$ statistically significant $(p \leq 0.05)$.

$N=84 ;{ }^{*}$ statistically significant $(p \leq 0.05)$.

Table 5. Factors influencing the knowledge scores among dental healthcare professionals (simple linear regression model)

\begin{tabular}{|c|c|c|c|c|c|}
\hline \multicolumn{2}{|c|}{ Variables } & Beta coefficient & $95 \% \mathrm{Cl}$ & $p$-value & $R^{2}$ \\
\hline \multicolumn{2}{|l|}{ Male sex } & -0.02 & $-1.04,1.00$ & 0.96 & 0.001 \\
\hline \multirow{4}{*}{$\begin{array}{l}\text { Age [years] } \\
\text { (20-30 as reference) }\end{array}$} & $31-40$ & 0.59 & $-4.38,1.66$ & 0.25 & \multirow{4}{*}{0.250} \\
\hline & $41-50$ & -0.21 & $-1.58,1.15$ & 0.75 & \\
\hline & $51-60$ & 2.90 & $0.90,4.91$ & $\leq 0.001^{* *}$ & \\
\hline & $>60$ & -8.29 & $-12.50,-4.07$ & $\leq 0.001^{* *}$ & \\
\hline \multirow{6}{*}{$\begin{array}{l}\text { Profession } \\
\text { (general dentists as reference) }\end{array}$} & dental assistants & -1.43 & $-2.75,-0.12$ & $0.03^{*}$ & \multirow{6}{*}{0.110} \\
\hline & orthodontists & 0.50 & $-1.07,2.08$ & 0.52 & \\
\hline & operative dentists & 0.04 & $-1.75,1.83$ & 0.96 & \\
\hline & maxillofacial surgeons & 0.70 & $-2.58,1.16$ & 0.45 & \\
\hline & prosthodontists & 0.04 & $-2.43,2.52$ & 0.97 & \\
\hline & periodontist & 2.04 & $-2.64,6.73$ & 0.38 & \\
\hline \multirow{2}{*}{$\begin{array}{l}\text { Workplace } \\
\text { (private hospitals as reference) }\end{array}$} & public hospitals & 1.31 & $-0.63,2.89$ & 0.20 & \multirow{2}{*}{0.040} \\
\hline & private clinics & -1.58 & $-1.51,1.19$ & 0.81 & \\
\hline
\end{tabular}

$N=84 ; C l$ - confidence interval; * statistically significant $(p \leq 0.05) ;{ }^{* *}$ statistically significant $(p \leq 0.001)$.

Table 6. Factors influencing the knowledge scores among dental healthcare professionals (multivariable linear regression model)

\begin{tabular}{|c|c|c|c|c|c|}
\hline \multicolumn{2}{|c|}{ Variables } & Beta coefficient & $95 \% \mathrm{Cl}$ & $p$-value & $R^{2}$ \\
\hline \multirow{4}{*}{$\begin{array}{l}\text { Age }[\text { years] } \\
\text { (20-30 as reference) }\end{array}$} & $31-40$ & 0.34 & $-0.77,1.46$ & 0.53 & \multirow{4}{*}{0.370} \\
\hline & $41-50$ & -1.47 & $-3.19,0.25$ & 0.09 & \\
\hline & $51-60$ & 2.25 & $0.24,4.25$ & $0.02 *$ & \\
\hline & $>60$ & -9.84 & $-14.24,-5.44$ & $\leq 0.001^{* *}$ & \\
\hline \multirow{6}{*}{$\begin{array}{l}\text { Profession } \\
\text { (general dentists as reference) }\end{array}$} & dental assistants & -1.32 & $-2.75,-0.12$ & $0.03^{*}$ & \multirow{6}{*}{0.370} \\
\hline & orthodontists & 0.55 & $-1.07,2.08$ & 0.52 & \\
\hline & operative dentists & 0.12 & $-1.75,1.83$ & 0.96 & \\
\hline & maxillofacial surgeons & 1.12 & $-2.58,1.16$ & 0.45 & \\
\hline & prosthodontists & 1.92 & $-2.43,2.52$ & 0.97 & \\
\hline & periodontist & 1.17 & $-2.64,6.73$ & 0.38 & \\
\hline
\end{tabular}

$N=84 ;{ }^{*}$ statistically significant $(p \leq 0.05) ;{ }^{* *}$ statistically significant $(p \leq 0.001)$. 
However, $68 \%$ of dental assistants, $60 \%$ of general dentists and $42 \%$ of dental specialists were not sure about the clinical protocols to minimize cross-infection.

\section{Discussion}

In the literature, there are several strategies outlined to deal with the SARS-CoV-2 infection. ${ }^{15-20}$ However, there is still no definitive treatment plan for this infection. The only possible way to deal with this healthcare crisis is to minimize the spread of SARS-CoV-2. ${ }^{14}$ Studies have found a strong association between the rapid spread of SARS-CoV-2 infection and the lack of knowledge regarding the infection, the personal protective equipment (PPE) and the guidelines for the PPE use among healthcare professionals. ${ }^{10,14,20}$

Dental specialists, however, showed a greater awareness regarding the spread of the virus as compared to dental assistants and general practitioners. This verifies the perceived hypothesis that due to more interest in theoretical knowledge and frequent attendance at the infection control seminars arranged for specialists by the policymaking organizations, dental specialists are more aware. Hence, the null hypothesis was rejected.

Furthermore, healthcare professionals' knowledge scores indicated the interest of the participants to find a solution to this pandemic. However, we found that only $63 \%$ of dental healthcare professionals responded to the survey questions correctly. This can be attributed to the versatile nature of SARS-CoV-2 symptoms, the associated myths, confusion among policy makers, and the lack of awareness among dental healthcare professionals.

The lack of awareness regarding the transmission of SARS-CoV-2 among dental assistants is worrisome, and may lead to drastic consequences for dental healthcare professionals and the patients' safety. The findings of this study are in agreement with previous studies. ${ }^{20-22}$ Nemati et al. conducted a survey on Iranian nurses and found that $94.11 \%$ had a low level of knowledge regarding SARS-CoV-2. ${ }^{22}$ This can be attributed to the fact that the researchers conducted their study at the beginning of 2020, when all healthcare professionals were not well aware of the SARS-CoV-2 safety protocols and guidelines.

We also found that dental staff members in the private sector were better aware of SARS-CoV-2 as compared to those working in public hospitals. These results may indicate the lack of resources as well as seminars on infection control protocols, and an increased number of workers of a low socioeconomic status in the public sector.

Another finding was that only $27 \%$ of dental professionals were well aware of proper hand hygiene and disinfection techniques after dental procedures. However, Nemati et al. found this percentage to be $57 \%$, which may have been due to the fact that the WHO had recently modified the CDC guidelines on infection control at the time of that study. ${ }^{22}$ The results suggest that policy makers should take steps to disseminate the updated CDC guidelines and policies among healthcare professionals by arranging frequent meetings and seminars. Also, the WHO should arrange seminars, webinars and meetings with healthcare workers in developing countries to share the updated facts, procedures and protocols to control this pandemic. ${ }^{17}$

The findings of this study are specifically associated with the South Asian population. However, some studies have shown that variations in the features of transmission of this infection are based on geography and ethnicity. ${ }^{11-14}$ This indicates a need for the development of guidelines for all demographic variations. It should be noted that this research was performed on the basic general guideline questionnaire provided by the CDC to restrict the transmission of communicable diseases.

\section{Conclusions}

To increase knowledge for dealing with the COVID-19 pandemic, hospitals should conduct mandatory workshops and seminars for all specialists and staff. We can extract the following conclusions from this study: dental healthcare professionals are now more concerned about measures for preventing the spread of the infection; dental specialists are better informed about disinfection protocols and the control of cross-infection as compared to dental assistants; and dental healthcare professionals are at least aware of the guidelines regarding the use of $\mathrm{PPE}$.

\section{ORCID iDs}

Hafsa Qabool (D) https://orcid.org/0000-0002-8968-2014 Rashna Hoshang Sukhia (D) https://orcid.org/0000-0001-9210-6432 Mubassar Fida (D) https://orcid.org/0000-0003-4842-9896

\section{References}

1. Szcześniak D, Gładka A, Misiak B, Cyran A, Rymaszewska J. The SARS-CoV-2 and mental health: From biological mechanisms to social consequences. Prog Neuropsychopharmacol Biol Psychiatry. 2021;104:110046. doi:10.1016/j.pnpbp.2020.110046

2. Wang YC, Lee YT, Yang T, Sun JR, Shen CF, Cheng CM. Current diagnostic tools for coronaviruses - from laboratory diagnosis to POC diagnosis for COVID-19. Bioeng Transl Med. 2020;5(3):e10177. doi:10.1002/btm2.10177

3. Ortiz-Prado E, Simbaña-Rivera K, Gómez-Barreno L, et al. Clinical, molecular and epidemiological characterization of the SARS-CoV-2 virus and the Coronavirus Disease 2019 (COVID-19), a comprehensive literature review. Diagn Microbiol Infect Dis. 2020;98(1):115094. doi:10.1016/j.diagmicrobio.2020.115094

4. Wadhwa A. Clinical features and disease stratification of COVID-19 in children. Indian J Pract Pediatr. 2020;22(2):137-143.

5. Ikoni O, Ogundele MO. The disruption of novel coronavirus (COVID-19) pandemic and quality of higher education in Nigeria. KIU J Human. 2020;5(2):25-36.

6. Rose-Redwood R, Kitchin R, Apostolopoulou E, et al. Geographies of the COVID-19 pandemic. Dialogues Hum Geogr. 2020;10(2):97-106. doi:10.1177/2043820620936050 
7. Sengupta S, Honavar SG, Sachdev MS, et al.; Writing Committee on behalf of the All India Ophthalmological Society - Indian Journal of Ophthalmology Expert Group for COVID-19 Practice Guidelines. All India Ophthalmological Society - Indian Journal of Ophthalmology consensus statement on preferred practices during the COVID-19 pandemic. Indian J Ophthalmol. 2020;68(5):711-724. doi:10.4103/ijo.IJO_871_20

8. Li JPO, Lam DSC, Chen Y, Ting DSW. Novel Coronavirus disease 2019 (COVID-19): The importance of recognising possible early ocular manifestation and using protective eyewear. $\mathrm{Br} J$ Ophthalmol. 2020;104(3):297-298. doi:10.1136/bjophthalmol-2020-315994

9. Peeri NC, Shrestha N, Rahman MS, et al. The SARS, MERS and novel coronavirus (COVID-19) epidemics, the newest and biggest global health threats: What lessons have we learned? Int $J$ Epidemiol. 2020;49(3):717-726. doi:10.1093/ije/dyaa033

10. Scrivener $S$, Yemaneberhan $H$, Zebenigus $M$, et al. Independent effects of intestinal parasite infection and domestic allergen exposure on risk of wheeze in Ethiopia: A nested case-control study. Lancet. 2001;358(9292):1493-1499. doi:10.1016/S0140-6736(01)06579-5

11. Wu Z, McGoogan JM. Characteristics of and important lessons from the coronavirus disease 2019 (COVID-19) outbreak in China: Summary of a report of 72,314 cases from the Chinese Center for Disease Control and Prevention. JAMA. 2020;323(13):1239-1242. doi:10.1001/jama.2020.2648

12. Shahdad S, Patel T, Hindocha A, et al. The efficacy of an extraoral scavenging device on reduction of splatter contamination during dental aerosol generating procedures: An exploratory study. $\mathrm{Br}$ Dent $\mathrm{J}$. 2020:1-10. doi:10.1038/s41415-020-2112-7

13. Miller RL, Burton WE, Spore RW. Aerosols produced by dental instrumentation. Proc First Internat Sym Aerobiol. 1963;4:97-120.

14. Vetta F, Vetta G, Marinaccio L. Coronavirus disease 2019 (COVID-19) and cardiovascular disease: A vicious circle. J Cardiol Cardiovasc Res. 2020;1(1):1-12. doi:10.37191/Mapsci-JCCR-1(1)-010

15. Dalewski B, Palka L, Kiczmer P, Sobolewska E. The impact of SARSCoV-2 outbreak on the Polish dental community's standards of care - a six-month retrospective survey-based study. Int J Environ Res Public Health. 2021;18(3):1281-1295.doi:10.3390/ijerph18031281

16. DePaola DP, Slavkin HC. Reforming dental health professions education: A white paper. J Dent Educ. 2004;68(11):1139-1150. doi:10.10 02/j.0022-0337.2004.68.11.tb03859.x

17. World Health Organization (WHO). Coronavirus disease (COVID-19) pandemic. 2020. https://www.who.int/emergencies/diseases/novelcoronavirus-2019. Accessed February 15, 2020.

18. Carlos WG, Dela Cruz CS, Cao B, Pasnick S, Jamil S. Novel Wuhan (2019-nCoV) coronavirus. Am J Respir Crit Care Med. 2020;201(4):P7-P8. doi:10.1164/rccm.2014P7

19. Zhu N, Zhang $D$, Wang $W$, et al. A novel coronavirus from patients with pneumonia in China, 2019. N Engl J Med. 2020;382(8):727-733. doi:10.1056/NEJMoa2001017

20. Khader Y, Al Nsour M, Al-Batayneh OB, et al. Dentists' awareness, perception, and attitude regarding COVID-19 and infection control: Cross-sectional study among Jordanian dentists. JMIR Public Health Surveill. 2020;6(2):e18798. doi:10.2196/18798

21. Market M, Angka L, Martel AB, et al. Flattening the COVID-19 curve with natural killer cell based immunotherapies. Front Immunol. 2020;11:1512. doi:10.3389/fimmu.2020.01512

22. Nemati $M$, Ebrahimi B, Nemati F. Assessment of Iranian nurses' knowledge and anxiety toward COVID-19 during the current outbreak in Iran. Arch Clin Infect Dis. 2020;15(COVID-19):e102848. doi:10.5812/archcid.102848 